\title{
It's time for a change of view in thyroid surgery?
}

\author{
Martinez Hurtado E.I, Sanchez Merchante M.2, Ripolles Melchor J.I, Aracil Escoda N.I, Tirado Errazquin A.I, Calvo \\ Vecino J.M.I. \\ AnestesiaR alrway Review Group (AIR Group) \\ I Infanta Leonor University Hospital, Dept of Anaesthesiology \& Intensive Care, Madrid, Spain, 2 Alcorcon \\ Foundation University Hospital, Dept of Anaesthesiology \& Intensive Care, Madrid, Spain
}

Background: True postoperative vocal cord (VC) paralysis (VCP) secondary to the injury of the recurrent laryngeal nerve $(R L N)$ is one of the major thyroid surgery complications, but with a low incidence, around $3 \%$, rising to $13 \%$ in reoperation.

Identifying the RLN visually during surgery can lower the incidence of RLN injury and the permanent injury rate of 0.9\%. IntraOperative Nerve Monitoring (IONM), electromyographic recording of the thyroarytenoid muscle activity after electrical stimulation of the vagus or RLN nerves, increases the safety for the patient reducing permanent injuries of RLN during thyroidectomy.

Materials and methods: We performed a search of the current literature about the use of IONM in thyroid surgery.

Diseussion: IONM can be done with an electromyographic endotracheal tube (EMGTET) which has a band with electrodes surface that should be placed at the level of the VC (I).

It's recommended direct visualization during placement of the EMGTET and a subsequent check (2), once placed the patient prior to surgery, and has been published the check of the placement when removes the Fiberoptic bonchoscopy (3), looking through the tube or with a direct laryngoscopy. But, since the repeated laryngoscopy can lead to the trauma and subsequent complication of ventilation, should be limited number of attempts.

Videolaryngoscopes (VL) allows accurate checking of the placement of the band between the VC with less trauma and complications.

Gonelusion(s): VL offers an improved view compared with traditional direct laryngoscopy. The method of laryngoscopy has a direct effect on the appropriateness of the choice of device for successful tracheal intubation. So that, in thyroid surgery, VL should be performed as routine intubation device.
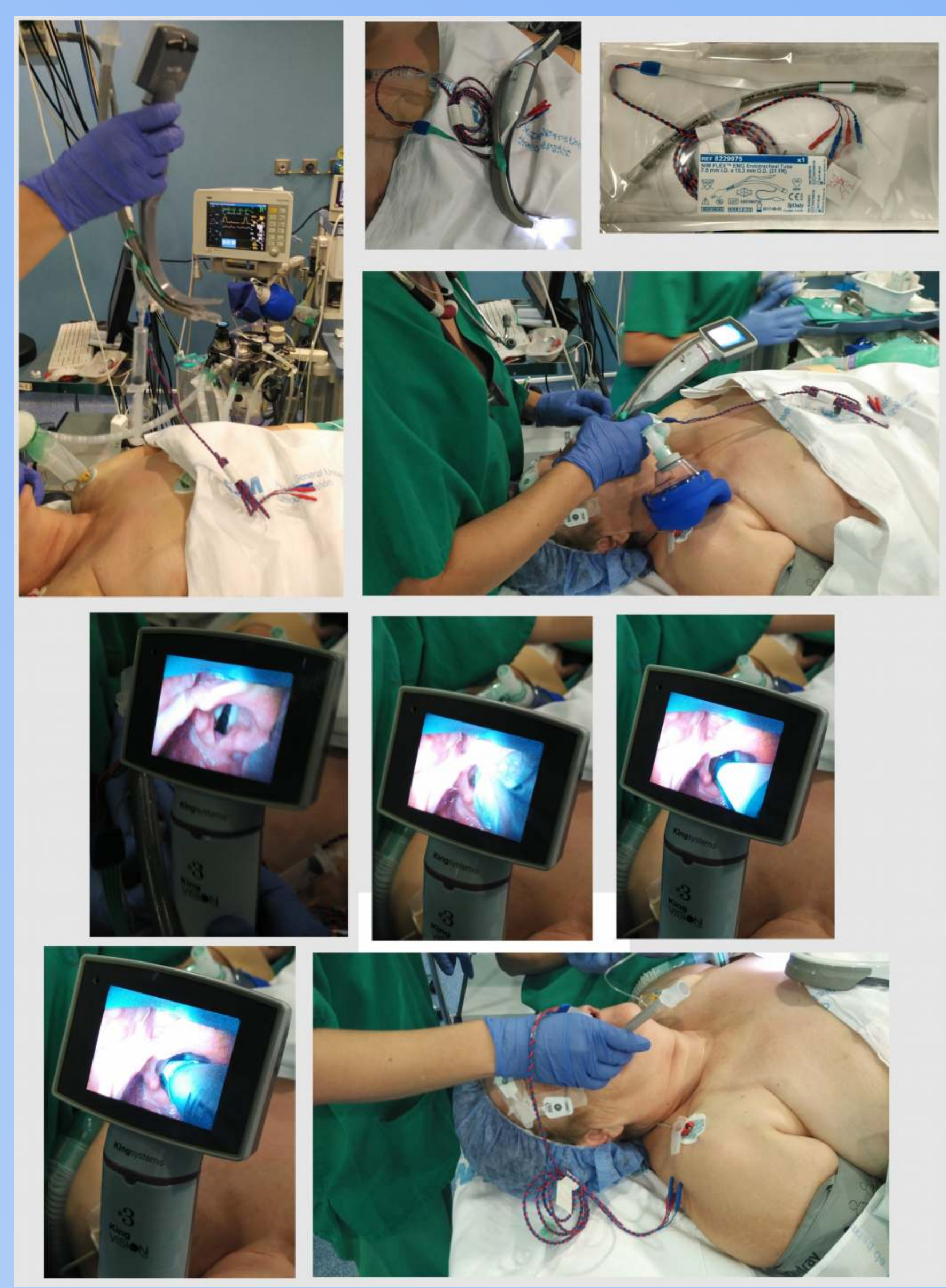

And Ear-Nose-Throat (ENT) surgery is considered a risk factor for difficult intubation, moreover thyroid surgery.

\footnotetext{
References:

1.- Martín Jaramago et al. Monitoring of recurrent laryngeal nerve injury using an electromyographic endotracheal tube in thyroid and parathyroid surgery. Anesthetic aspects. Rev Esp Anestesiol Reanim. 2013 Dec;60(10):576-83.

2.- Lu IC et al. Optimal depth of NIM EMG endotracheal tube for intraoperative neuromonitoring of the recurrent laryngeal nerve during thyroidectomy. World J Surg. 2008 Sep;32(9):1935-9.

3.- Tahery J, Natt RS. Fibre-optic laryngoscope and endotracheal tube assembly: how we do it. Clin Otolaryngol. 2010 Aug;35(4):327-9.
}

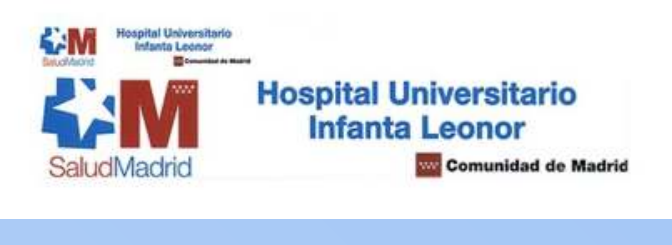

